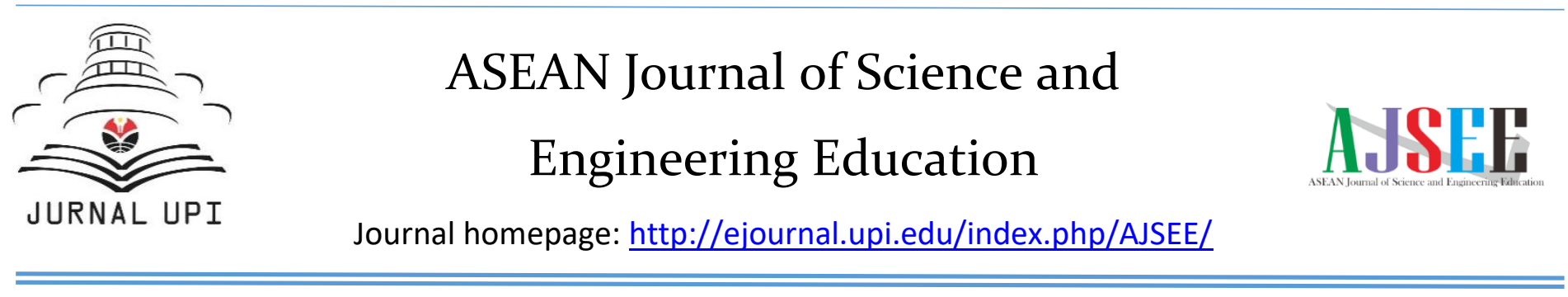

\title{
Perceptions of Millennials on Filipino Superstitious Belief
}

\author{
Adonis S. Besa Ph.D*, Hassanal P. Abusama M.AT, Genebelle M. Lao, Elyza G. Abraham, Fareeda de la Cruz, \\ Sheena L. Duldulao, Seth Nahzier S. Perocho
}

Sultan Kudarat State University - LSHS, Tacurong City, 9800 Sultan Kudarat, The Philipines.

Correspondence: E-mail: genebellelao@sksu.edu.ph

\begin{abstract}
A B S TR A C T S
This study aims to cater to the millennials' perceptions of Filipino Superstitious Beliefs and how they can affect one person's behavior and performance. The study investigated the following questions: (1) What are the reasons why the chosen respondents believe in superstitions? (2) What are the effects of superstitions on the lives of millennials? (3) What are the perspectives of millennials nowadays on some Filipino superstitious beliefs? (4) How can superstitious beliefs affect one person's performance and behavior? We used the qualitative method, specifically phenomenological in the research design. We conducted interviews and questionnaires. Data was recorded, analyzed, classified, and organized using necessary measurements and analyses. Believing in superstitions can be one of the basic traditions that are taught to Filipinos while they growing up. It is proven that not all millennials have forgotten the sense of believing in some Filipino superstitious beliefs. All responses from the participants had different senses of values. They also do have the same idea on how they can give back respect to our ancestors. Being superstitious can influence perspectives, giving impact to everything for making execution and decision. Indeed, it is on a specific test to the response to fake treatments. The study found out that millennials still believe in the power of superstitions based on their experiences, the traditions of their old ones, or even the ancestors. This study is an approach to clarify the understanding of superstitions in the current time.
\end{abstract}

\author{
ARTICLE INFO \\ Article History: \\ Submitted/Received 27 Mar 2021 \\ First Revised 7 Apr 2021 \\ Accepted 11 Apr 2021 \\ First available online 11 Apr 2021 \\ Publication date 01 Sep 2021 \\ Keyword: \\ Ancestors, \\ Behaviour \\ Filipino superstitious beliefs, \\ Millennials, \\ Perceptions,
}




\section{INTRODUCTION}

Combined with everyday living, superstition had entangled itself with the truth of common daily events. As superstitions and science both existing in the current generation, we are enabled to discern the choices to be taken, whether which of the two we should always rely upon (Razon, 2020).

Being superstitious can influence your conduct and perspective, impacting everything from your execution on a particular test to your responsiveness to fake treatments (Li, et al., 2020; Sultana, et al., 2019). Superstitions appear to be a more complicated concept than merely a perception than an unrelated behavior (or object) can improve performance (Ichino, 2020). The legitimacy of superstitions depends on confidence within the intensity of enchantment and magic (Zad, 2014). Somehow the supernatural beliefs and practices of their ancestors still exert a major influence in the daily lives of modern Filipinos. (Luna, et al., 2019). Superstitions belief also could affect housing market (He, et al., 2020), school outcomes (Mocan and Yu, 2020), financial decision (Hirshleifer, et al., 2018), schooling laws (Mogan and Pogorelova, 2017), and stock price (Bai, et al., 2020). However, there is no study of superstitious beliefs conducted among Filipino millennials. The Millennials are quite opposite of their predecessors, Generation X (Monaco and Martin, 2007). This research aims to spot a millennial's perspective on Filipino Superstitious Beliefs and to spot its effect in an exceeding person's life also an approach to clarify the understanding of superstition and to know its condition in the current time.

\section{METHODS}

The research design used in this study is the qualitative specifically phenomenological research design. Phenomenological research is an approach to qualitative research that focuses on the commonality of a lived experience within a particular group. To gather the data, we conducted interviews with the use of guide questionnaires that will contain information about the different perspectives of millennials for Filipino superstitions and beliefs. After the collection of data, it was recorded, analyzed, classified, and organized using necessary measures in determining the results. Responses are analyzed through multiple steps, translated, and sorted. The researchers transcribed and did the initial analysis of the raw data. After all the interviews were transcribed, similar responses were categorized into a theme. All themes were identified by title and then defined by the primary researcher (Vernacchia, et al., 2000).

\section{RESULTS AND DISCUSSION}

Table 1 shows contextualized themes from the key informants responses. The majority of the respondents got similar answers to the research original question: As a millennial, what are your perceptions on some superstitious beliefs (Trianti, 2021). They are taught by the elders to follow what is said, to give honor and respect to our ancestors which are roots wherein all the superstitions that are still known in the present started. Believing in superstitions can be one of the basic traditions that is taught to us Filipinos while growing up (Abad, 1995). Superstitions, given meaning by the participants can be both; charm, and bad luck (Umesan, et al., 2020). The purpose of this study is to qualitatively analyze and why and how a millennial will approach when they hear the word "superstitious beliefs". All themes were placed into a table with quotes and key informants that supported the said theme. We refined each theme based on the quotes from the participants. This is important as reported in literature (Wisniawati and Rasiban, 2021). 
Table 1. The COD and BOD values for the last week of the month (final clarification output).

\begin{tabular}{lll}
\hline \multicolumn{1}{c}{ THEMES } & & \\
\hline Thoughts on & - Matter of application \\
Superstitious Beliefs & - & Depends on family culture and traditions \\
Matter of & - It must be fulfilled \\
Application & - Value; depends in the family practice \\
Connection between & - & - Tppreciation or thinking it can be good \\
belief and behavior & - "it is for you to be alert" \\
Reasons behind & - "the more you believe, most likely it will happen" \\
belief & - Learnings for the future \\
Importance of & - Millennials are the bridge from the ancestors to the next generation, Gen Z \\
superstitions & - Awareness \\
& - Learnings for the near future
\end{tabular}

There are some superstitions taught by the elders that happen to become true and some that they think are not really convincing so they intend to stop practicing it and is also a result of the advancement of technology (Qotrunnada and Nurani, 2021). Our respondents focused more on appreciation because it is handed down to us by our ancestors and the millennials can be the very bridge on to the next generations and to let them prove that the ancestor's hard work still lives on, also for them to be aware in our surroundings, so that they cannot harm themselves or other people as well ( $\mathrm{Ng}$, et al., 2010). Also in our study, there is valuable information collected in the fact that our respondents had maintained the practice of superstitions until the present time even though technology has already taken over into the modern world (Wakefield, et al., 2017).

\section{CONCLUSION}

The study found out that millennials still believe in the power of superstitions based on their traditions. Their belief still depends on the matter of the application of the family, peers, or even their own experiences. When an existing superstition is experienced, there are only two choices; it is to believe or not but others may think that it is just a coincidence and others might get frightened so they will come up with an idea that they will be more careful and avoid doing the specific belief.

\section{ACKNOWLEDGEMENTS}

We thank to Sir Hassanal P. Abusama, MAT, subject teacher, and Sir Adonis S. Besa, MA. PhD, co-adviser who gives us support, guidance, teaches us how to do the step-by-step processes, and allowed us to conduct our research study.

\section{AUTHORS' NOTE}

The authors declare that there is no conflict of interest regarding the publication of this article. Authors confirmed that the paper was free of plagiarism.

\section{REFERENCES}

Abad, R. G. (1995). Filipino religiosity: Some international comparisons. Philippine Studies, 43(2), 195-212. 
Bai, M., Xu, L., Yu, C. F. J., and Zurbruegg, R. (2020). Superstition and stock price crash risk. Pacific-Basin Finance Journal, 60, 101287.

Hirshleifer, D., Jian, M., and Zhang, H. (2018). Superstition and financial decision making. Management Science, 64(1), 235-252.

Ichino, A. (2020). Superstitious confabulations. Topoi, 39(1), 203-217.

Li, Y., Wang, K., Ji, X., and Tang, Y. (2020). Financial psychology analysis of numerical superstitions and stock price volatility: Empirical evidences from China's A-share market. Revista Argentina de Clínica Psicológica, 29(1), 279.

Luna, M. L., De Guzman, A. A., and Lacorte, J. L. (2019). Level of practice of superstitious beliefs among the students of callejon national high school: Basis for scientific literacy campaign. Tonyo's Journal. 1(1), 21-35.

Mocan, N., and Yu, H. (2020). Can superstition create a self-fulfilling prophecy? school outcomes of dragon children in China. Journal of Human Capital, 14(4), 485-534.

Monaco, M., and Martin, M. (2007). The millennial student: A new generation of learners. Athletic Training Education Journal, 2(2), 42-46.

$\mathrm{Ng}, \mathrm{T}$. , Chong, T., and Du, X. (2010). The value of superstitions. Journal of Economic Psychology, 31(3), 293-309.

Qotrunnada, Q., and Nurani, A. S. (2021) Teenagers Knowledge About Traditional West Java Cakes. Indonesian Journal of Community and Special Needs Education, 1(1), 15-18.

Razon, B. C. (2020). COVID 19: Impetus for "Community Spirits" among Filipinos. Indonesian Journal of Science and Technology, 5(2), 201-208.

Sultana, Z., Chowdhury, L., and Shapla, N. R. (2019). Study on superstitions related to pregnancy. Journal of National Institute of Neurosciences Bangladesh, 5(2), 172-176.

Trianti, R. (2021) The existence of Sunda Wiwitan among Sundanese people as a local belief in Indonesia. Indonesian Journal of Community and Special Needs Education, 1(1), 19-24.

Umesan, U. K., Bakar, N. A., Sani, S., and Balakrishnan, P. (2020). A veil of superstition unveiled-an exotic manifestation of susuk. International Journal of Research and Reports in Dentistry, 3(2),30-34.

Vernacchia, R. A., McGuire, R. T., Reardon, J. P., and Templin, D. P. (2000). Psychosocial characteristics of Olympic track and field athletes. International Journal of Sport Psychology, 31(1), 5-23.

Wakefield, J. C., Shipherd, A. M., and Lee, M. A. (2017). Athlete superstitions in swimming: Beneficial or detrimental?. Strategies, 30(6), 10-14.

Wisniawati, W., and Rasiban, L. M. (2021) Japanese pop culture (anime, j-pop, dorama) in increasing motivation to learn Japanese. Indonesian Journal of Educational Research and Technology, 1(1), 5-6.

Zad, R. E. (2014). Superstitious beliefs and some of its causes (case study: ghachsaran citizens). Bulletin of Environment, Pharmacology and Life Sciences, 3, 286-290. 